Edited by:

Carmen Sandi, Ecole Polytechnique Fédérale de Lausanne, Switzerland

Reviewed by:

Valerie J. Bolivar, Wadsworth Center, NYSDOH, USA

Andrew Holmes, National Institute on Alcohol Abuse and Alcoholism, NIH, USA

* Correspondence:

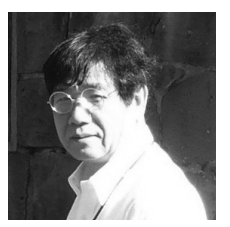

Tamotsu Hashimoto-Gotoh obtained his DSc from Kyushu University in 1977. After post-doctoral work at the Max-Planck Institute for Molecular Genetics in Berlin with Kenneth Timmis, he became B1 Wissenschaftler at German Cancer Research Centre in Heidelberg with Günther Schütz, and was then invited to Hoechst AG for establishing Molecular Biology Laboratory at R\&D Laboratories, Hoechst Japan Limited, in Kawagoe, where he was engaged in research fields of Oncology, Hematology, and Bone Biology. Then, he became Associate Professor of Biochemistry and Molecular Genetics at Research Institute for Neurological Diseases and Geriatric, Kyoto Prefectural University of Medicine, where he obtained DM in 1996. thg@koto.kpu-m.ac.jp

\title{
KF-1 ubiquitin ligase: an anxiety suppressor
}

\section{Tamotsu Hashimoto-Gotoh ${ }^{1 *}$, Naoyuki Iwabe ${ }^{2}$, Atsushi Tsujimura ${ }^{1}$, Keizo Takao $^{3,4,5}$ and Tsuyoshi Miyakawa ${ }^{3,4,5}$}

\author{
Department of Biochemistry and Molecular Genetics, Research Institute for Neurological Diseases and Geriatrics, \\ Kyoto Prefectural University of Medicine, Japan \\ 2 Department of Biophysics, Graduate School of Science, Kyoto University, Japan \\ 3 Institute for Comprehensive Medical Science, Fujita Health University, Japan \\ 4 Frontier Technology Center, Kyoto University Graduate School of Medicine, Japan \\ ${ }_{5}$ Japan Science and Technology Agency, BIRD \& CREST, Japan
}

Anxiety is an instinct that may have developed to promote adaptive survival by evading unnecessary danger. However, excessive anxiety is disruptive and can be a basic disorder of other psychiatric diseases such as depression. The KF-1, a ubiquitin ligase located on the endoplasmic reticulum (ER), may prevent excessive anxiety; $k f-1^{---}$mice exhibit selectively elevated anxiety-like behavior against light or heights. It is surmised that KF-1 degrades some target proteins, responsible for promoting anxiety, through the ER-associated degradation pathway, similar to Parkin in Parkinson's disease (PD). Parkin, another ER-ubiquitin ligase, prevents the degeneration of dopaminergic neurons by degrading the target proteins responsible for PD. Molecular phylogenetic studies have revealed that the prototype of $k f-1$ appeared in the very early phase of animal evolution but was lost, unlike parkin, in the lineage leading up to Drosophila. Therefore, $\mathrm{Kf-1}^{-1-}$ mice may be a powerful tool for elucidating the molecular mechanisms involved in emotional regulation, and for screening novel anxiolytic/antidepressant compounds.

Keywords: depression, ERAD pathway, Parkinson's disease, Alzheimer's disease, animal evolution

\section{INTRODUCTION}

Anxiety, or learned fear, is not necessarily harmful to everyday life but, rather, is a natural ability that may have arose to evade unnecessary dangers. However, excessive anxiety is debilitating or disadvantageous for life as it reduces behavioral activities necessary for adaptation. Moreover, anxiety can be a core symptom of various mental/ behavioral disorders, such as major depressive disorders, obsessive-compulsive disorders, panic disorder, adaptive disorder, post-traumatic stress disorder, social withdrawal disorder, and various phobias. Patients with anxiety/depression interpret circumstantial incidences, including episodes, comments, and expressions, in a negative way. The interpretation leads individuals to enhanced capture or delusions caused by potential signs of danger. This suggests that a system of negative and positive regulation of the emotional expression may have developed under the evolutionary constraint. Such a system would be most apparent in highly social animals with relatively little reproduction per generation, like humans (Darwin, 1872). Indeed, there is evidence that the amygdala is responsible for the expression of anxiety or fear, and the prefrontal cortex plays a role in fear extinction by regulating the amygdala-mediated expression of fear (see Bishop, 2007). Although the molecular mechanisms underlying negative and positive regulation of the anxiety are not fully understood, many genes have been reported to affect anxiety or fear (Chen et al., 1994; Gogos et al., 1998; Heisler et al., 1998; Holmes et al., 2003; Miyakawa et al., 1994, 
2003; Nakajima et al., 2008; Yamasaki et al., 2008). Among these, the genes related to the serotonergic system are seen to be of special interest. For example, human genomic studies of anxiety/ depression have focused on genes related to the monoaminergic neurotransmission of serotonin receptors $\left(5-\mathrm{HT}_{1 \mathrm{~A}}\right)$ and transporters $(5-\mathrm{HTT})$ (see Levinson, 2006; Uher and McGuffin, 2008). Genetic studies using gene-targeting techniques have revealed that knockout mice lacking either 5 - $h t_{1 A}$ or 5-htt exhibit significantly increased anxiety-like behaviors (Heisler et al., 1998; Holmes et al., 2003). However, proteins that interact directly with neurotransmitters seem to function downstream, rather than upstream, of the serotonergic pathway.

Anxiety/depression is the most common psychiatric disease seen in patients irrespective of nations, societies, and religions. Consequently, pharmaceutical companies have made extensive worldwide efforts to develop anxiolytic/ antidepressant drugs, particularly serotonergic compounds such as selective serotonin reuptake inhibitor (SSRI) and serotonin noradrenalin reuptake inhibitor (SNRI) based on the monoamine hypothesis. The hypothesis assumes that the pathogenesis of depression is caused by the depletion of monoamines such as serotonin in the brain. This assumption has however not been proven in the last 60 years. Testing systems have been developed for rodents to measure behavioral despair and to screen serotonergic drugs. These include the forced swim test and the tail suspension test. Compounds that elevate monoamine levels in the brain reduce the despair-like behavior or immobility time of animals under fearful conditions (Porsolt et al., 1978; Steru et al., 1985). However, approximately one-third of the patients with anxiety/depression do not respond to the serotonergic drugs, suggesting that despair-like behavior in rodents does not precisely represent anxiety/depression in humans, from a pharmacological point of view. Therefore, it is desirable to have some genetic animal models that display excessive anxiety-like behavior specifically without affecting despair-like behavior, as observed in the $k f-1^{-l-}$ mice (Tsujimura et al., 2008), to look for novel anxiolytic/antidepressant drugs that are effective in patients who do not respond to serotonergic drugs.

A type of zinc binding domains, similar to RING finger motif containing a $\mathrm{C} 3 \mathrm{HC} 4$ amino acid motif for binding to two zinc ions. RING-H2 finger motif contains two histidine residues as in $\mathrm{C} 3 \mathrm{H} 2 \mathrm{C} 3$ motif.

Many of the RING finger domains function as ubiquitin ligases.

\section{IDENTIFICATION AND NATURE OF KF-1} in connection with Alzheimer's disease (AD). Genetic studies of familial AD (FAD) made significant progress in 1990s. In this period, three genes encoding $\beta$-amyloid precursor protein,
The gene for KF-1 was originally discovered pressenilin-1 (PS1), and presenilin-2 (PS2) were identified as the causative genes for FAD (see Hashimoto-Gotoh et al., 2006; Lundkvist and Näslund, 2007), and two other genes were found expressed more frequently in the frontal cortex of an $\mathrm{AD}$ patient than a non-AD subject (Yasojima et al., 1997). One of the later two genes, gfap, was a known gene encoding glial fibrillary acidic protein, and the other was a novel gene, named $k f-1$. The $k f-1$ gene is expressed most prominently in the brain and more or less throughout the entire body, but least, if any, in the liver, which implies that $k f-1$ may not be a housekeeping gene. Human $k f-1$ has four exons ranging over approximately $30 \mathrm{~kb}$, and is mapped to chromosome $2 \mathrm{p} 11.2$. The protein structure deduced from the cDNA sequences has revealed that human KF-1 protein (GenBank Acc No. BAA19739) consists of 685 amino acids, and contains a possible leader peptide (amino acid positions 1-19), two membranespanning segments (326-345 and 366-380), and a RING-H2 finger motif (621-662) close to the C-terminus (Figure 1A). KF-1-like proteins have been found in other animals including fish (Danio rerio), lancelet (Blanchistoma floridae), sea urchin (Strongylocentrotus purpuratus), sea anemone (Nematostella vectensis), and tablet animals (Trichoplax adhaerens) (Figure 1A). Molecular phylogenetic studies suggest that genes for the animal and vertebral proteins may be $k f-1$ orthologues (Figures 1B,C, respectively). Unexpectedly, KF-1 homologues do not exist in insects (Drosophila melanogaster) and thread worms (Caenorhabditis elegans, and C. briggsae), even though it is likely that the prototype gene appeared in the very early phase of animal evolution, before the separation of Placozoa and Eumetazoa (Miller and Ball, 2008; Srivastava et al., 2008). Homologues of the prototype do not exist in prokaryotes, plants, or fungi, but are found first in one of the most primitive multicellular animals, such as tablet animals (Schubert, 1993) (Figure 1D). The results may be consistent with the report based on the EST analysis that some genes, formerly thought to be vertebrate inventions, must have been present in the common metazoan ancestor (Kortschak et al., 2003). Choanoflagellates (Monosiga brevicollis, and M. ovata), supposedly one of the most closely related unicellular protists to animals (King et al., 2008), do not possess $k f-1$ (Figure 1D).

The KF-1 protein is an E3 ubiquitin ligase that may modulate the cellular protein levels of its unknown substrate(s) (Lorick et al., 1999). The expression of $k f-1$ is also increased in the frontal cortex and hippocampus after chronic administration of SSRI in rats (Yamada et al., 2000). Furthermore, rat $k f-1$ expression is elevated 
Hs MWL-------KLFFLLLYFLVLFVLARFFE-AIVWYETGIFATQLVDPVALSFKKLKTTILECRGLGYSGLPEKKDVRELVEKSGDLMEGELYSALKEE-EASESVSSTNFSGEMHFYELV 111

Dr MWW------KLFFLLLYFFILF ILARFFE-AIVWYETGIFATQLVDPVTLSFKKLKT ILECRGLGYSGLAEKRDVRELVENSGELMQGELYSALKNEKEQAGSDSSTTFSGEMHFYELV 112

Bf MLV-------RLLLLLVYLCLLLVAVRLLE-AATWFEAGFLAGQVLDPLSISVRRLKMILDSRGISYKGVLEKKELTTDLVENSGEPKEGEVLLAAE---DEDTEPTSTNFTGRAHFYEEV 109

Sp MFM------KKIVFLLVYATLLFLLARMLE-YIPWYQTGLLMMKLIDPVSLSVKKLKSLLDGRGLSYEGVIDKAELTQLVEESGHVMEGEVLMMEQDASEREEEEEPTTTTFSSHA---- 109

NV MLT-------KLLLLLVYFFLIFLTTRFLELTASWFEAGCIASQLFDPLSLSVRKLKAILDQRGVSYNGVVEKSELADLVEVSGAVTDPESALTAQGSNDNEQNSDEFTFKGASHFFEEV 113 MTAGWFLTAIKIILLIVYLICVLLSCKYWN-VQLWKVGDKAARLLLDPATFNLKELIEIIDYRGVSDLNLHDRTNLSYMVNASGLMSEEEKWQSAIIM-AQSKKREAINFTAENYLRAEI 118

CS

L Y

DP L RQ

V SG E

********************************************************************$\quad * * * * * * * * * * * * * * * * * * * * * * \quad 240$

Hs EDTKDGIWLVQVIANDRSP--LVGKIHWEKMVKKVSRFGIRTGTFNCSSDPRYCRRRGWVRSTLIMSVPQTSTSKGKVMLKEYSGR--KIEVEHIFKWITAHAASRIK--TIYNAEHLKE 225 EDTKDGIWLVQVIAQDRNP--LLSTANWGKMVQKVSQFGIRTGTFNCSSDSRYCHKRGWMKSTLIMSVPQTYASKGKVMLKEYNGR--RIETEHIFKWMTAHVASRIK--TVRYSDQLMD 226 EDTKDSVWLVQVIPEDHIP--LLGPQQWKSLVRKVSRFGIRTGTFKCQLDRKLCWRKGWDRPSLALALPRGHQAKGHISVQVFNT---PSKEQTILDWINQHLSSRTH--SVLSPHQLQT 222 ------QFSEEVIPRNFGP--LLGKRAWSTVVKKLSRFGIRHGTFDCSIEPSICPRKNWINLPLLLLAMPQGHRHKGQVTMAKFTS---EGKAQQIINWVYLELAKKVN--TERGFGQ-EY 215 EDTKAGSWLVEVIPENHIP--LLRRKQWSSLKRKMRLFGIRTGSFKCEEDPWLCRKYKWNNRPSLVLSMPKGNQPKGNVILQTYQA---KPNVNSVLLWINSELSSKVI--ELDSTNTLLNK 226

$===== \pm$ DW---YQMEKQPVKMFLFARLLQPPAFFSALSIKFTGRIEFIFVD---VRNWDNNTCLEEIGVQQMPSY ILKTPEGIYRYGNSTGEFISLHAMDTFLRSVQPEVNDLFILSLVMVNLMAW 340 DW--LMKNRTHPVQVVFFSRLKQPPMFYSALSVKFTGRVKFGYMR---LNNSRNRLDIS--GREKIPGILVITPERRYWYGTGKGELLNLQSMQTYLRTMQPEVNDIFLVCVVVVNLLMAV 335 DWDKLESNRDVAVKVVLFSRNQEPPVFFSALNLKYSGRVKFVFVS---DSKTFYVLDNR-AQKYWLPSYIIVTPEGKKVYGENNGEYCTYSALDLYLQILSPEANDIFVLTF INVNAICF 331 IL--QSDRDPNYIYVVYHSTLTEPPMFLSSLSIKFTGRVKFVYCR---SHLKHRKEDIN-FDGFKVPSLFVITPERRVLFGLKKGEIYDYSSLELYLRTLHPEVNDLFLAALVITNLCCM 340 TI-----KKQSGIHVILFSTLTVAPTFISSLAIKFSGRINFSMVTIKTINDTIQNLFANEFNVEKLPTYRIFTPEKNFTYGNRHGEYYGYHCHHEFLTSLYPATNDIFVAIVIG INLHCL 353

$$
\begin{array}{lllllllll}
\text { P F S L } & \text { K } & \text { GR } & \text { F }
\end{array}
$$$$
\text { P TPE G GE }
$$$$
\text { L } \quad P \quad \text { ND F }
$$

$\mathrm{N}$ MDLFITQGATIKRFVVLISTLGTYNSLLIISWLPILGFLQLPYLDSFYEYSLKLLRYADTTTIASWVRAD-WTFYSSHPALFLSTYLAHGLLIDYFEKKRRRC---SNEDQ-NANNLEWL- 454 LEVFLCGGQVGVGVLRLLWAVGKYNCVLLMVCLPVVGLFQLPCMEGVVQAGLTALRNISSSGLVAQARQD-WLLYSSHKPFLVGTFLLYSMAVGIVASRWKS-GEEMASETTPTEQAGT- 452 MGLFLIQGGIAKRICGFLWTIGKYNITLILLWLPLLGIIQLPFLASVQDYSYKMLRLSSQTWLIGKLRQD-WMMYSGHSYIIIGSFLLYCVAVNWVAKK IQA---PTNEDSMTSAM-WLR 446 LESFLIHGGILRRTFRLLCMLTFYNTSLIMLCLPMVWLFQLPFLQPVLDFTLKCCRCIMSGDIASLLRHD-LMFWMNYDYFVLIGYFVFGFTLGYIRNKYKCYFGVGDDDLEDPNADWL- 458 LKLLLIDGTFLACLLKF IILFCQYNFAVVLLWFPMYNFFTSPLMHIVYDLTMMVMRCLMGTDFVAAIRRSTHLTHPGCLFMLLTESIIFASVIYYWIECQEG--QISGTESMA-SCNYL- 469 G YN $\mathrm{P} \quad \mathrm{P}$ $\mathrm{R}$ 


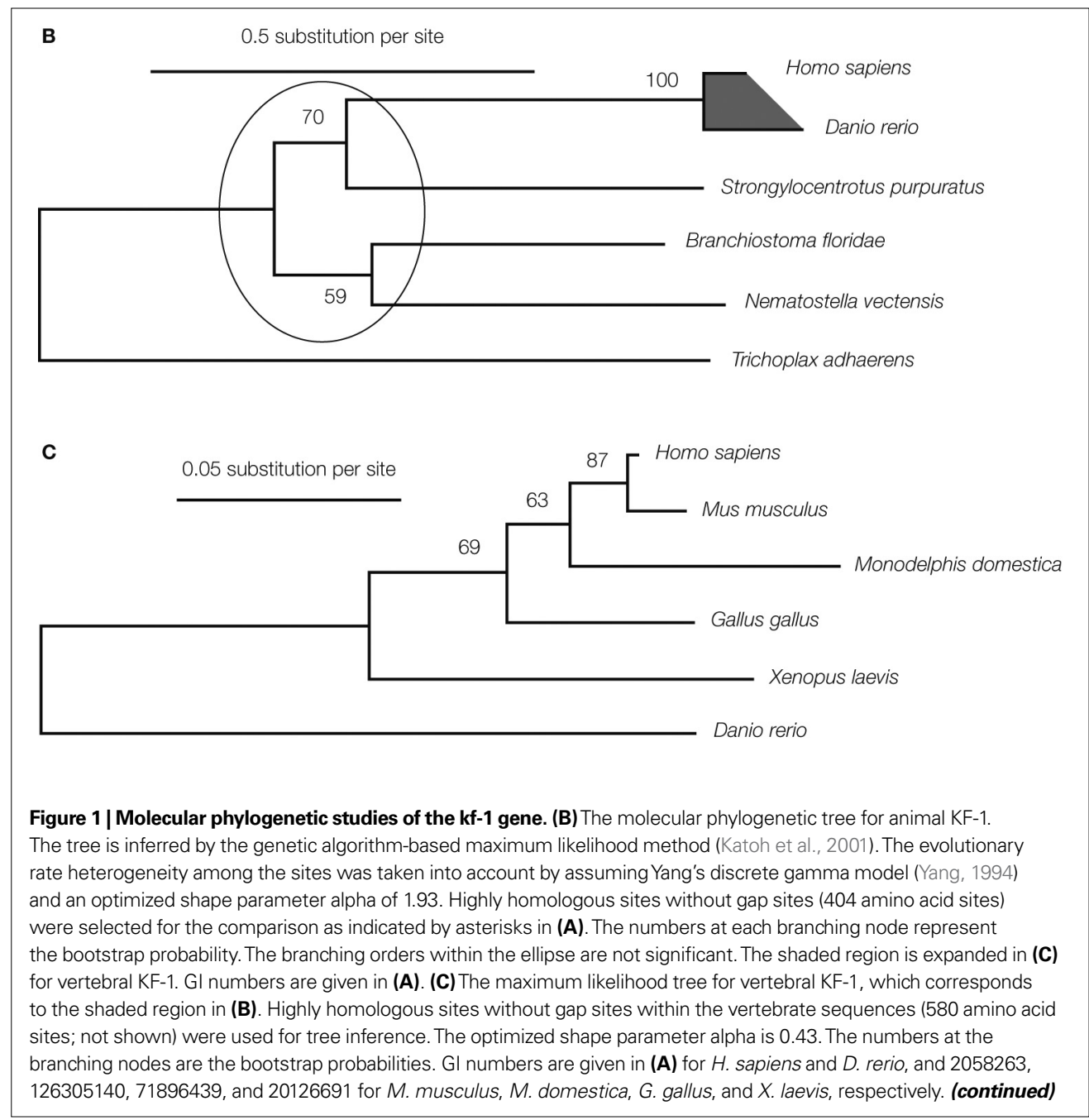

Molecular phylogenetic tree A diagram showing the evolutionary relationship or history of organisms, genes or proteins. It is inferred by a phylogentic method such as neighbor-joining, maximum parsimony, or maximum likelihood, based on the nucleotide or amino acid sequences of various species. after physical antidepressant treatments, such as electroconvulsive therapy (Nishioka et al., 2003), and repetitive transcranial magnetic stimulation (Kudo et al., 2005). This implies that the upregulation of $k f-1$ expression is associated with some physiological responses to antidepressant treatments rather than being caused by a chemical reaction to serotonergic compounds such as SSRIs. It was, however, not clear whether this was a result, cause, or coincidental side effect of antidepressive processes.

As a possible correlation between KF-1 and AD has been suggested (Yasojima et al., 1997), and as depression can occur early in the course of $\mathrm{AD}$ in $p s 1$ mutation carriers unaware of their genetic status (Ringman et al., 2004), the first working hypothesis was that presenilins could be KF-1 substrates in the endoplasmic reticulum (ER) associated degradation (ERAD) pathway (see Carvalho et al., 2006; Lorick et al., 2006). Therefore, the intracellular localization of KF-1 was examined in comparison to that of presenilins known to be located on ER (Kovacs et al., 1996). The results have revealed that KF-1 is co-localized with both PS1 and PS2 (Figures 2A,B and Tsujimura et al., 2008), which implies that KF-1 may in fact be an ER-ubiquitin ligase. The co-localization of KF-1 with other ER markers, such as Der-1 and VCP, has also been observed (Maruyama et al., 2008).

\section{SELECTIVE EXPRESSION OF INCREASED ANXIETY-LIKE BEHAVIORS IN $\boldsymbol{k f}^{-1^{--}}$MICE}

Although mouse $k f-1$ is expressed in many tissues, particularly in the brain, the lack of $k f-1$ does not lead to any abnormalities in appearance or behaviors, including body weight, reproductive capability, exploratory locomotion, nociception, social behavior, motor coordination, behavioral despair, spatial working memory, and context memory (Table 1).

The exception is that $k f-1^{-1-}$ mice display a pronounced increase in anxiety-like behavior in the light/dark transition test (stay time in light compartment: $p=0.0004$; number of 
D

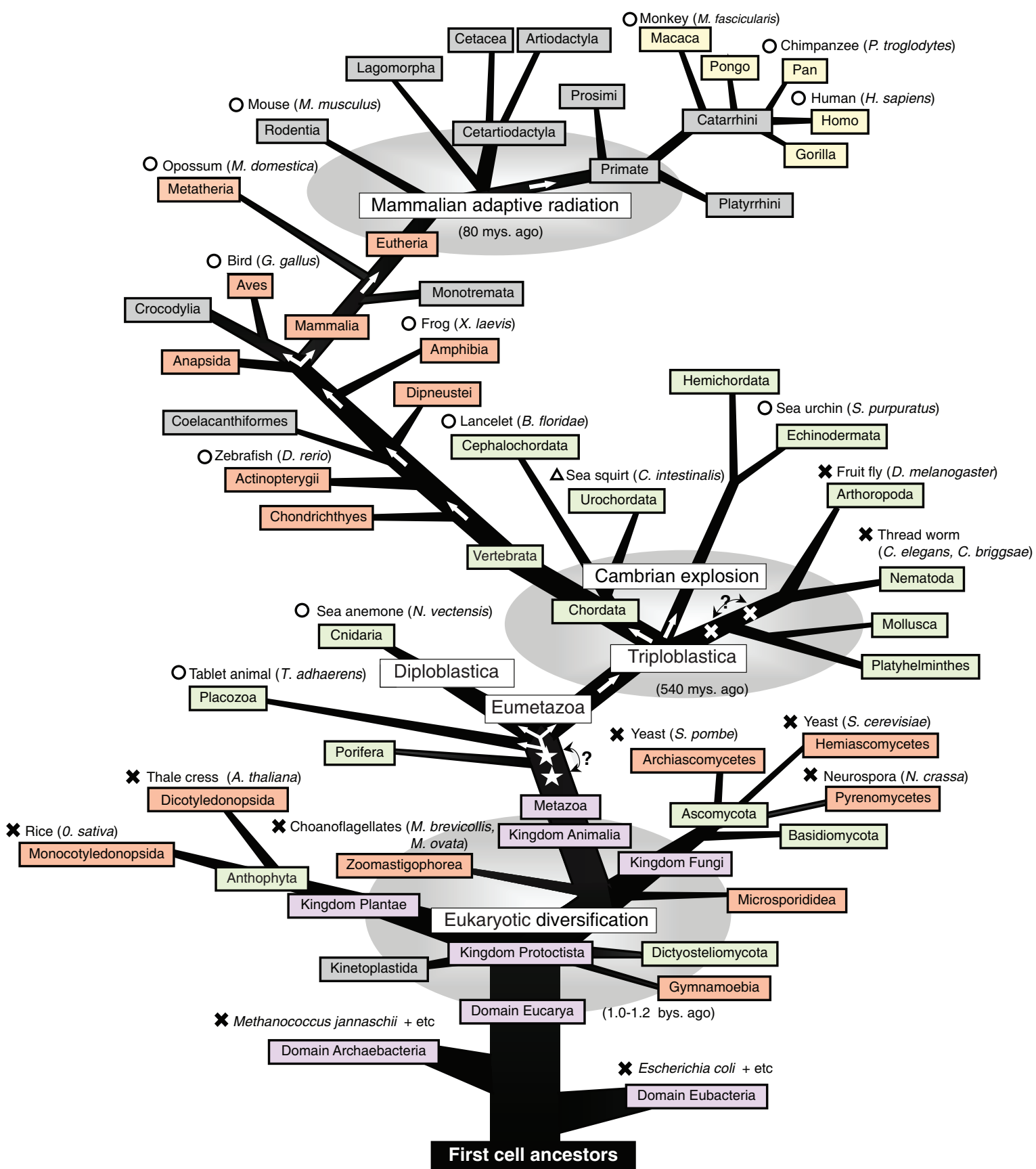

, Kingdoms/Domains;

, Phyla/Divisions;

Classes;

Orders;

Genera.

Figure 1 | Molecular phylogenetic studies of the $\boldsymbol{k f - 1}$ gene.

(D) Presence/absence, generation, and transmission of $k f-1$ on the evolutionary tree of life. The tree is essentially the same as the one, that was previously presented (Hashimoto-Gotoh et al., 2003), with minor modifications and corrections except for the genes concerned. '?' with bi-arrows and two open stars or crosses denotes uncertainty of the precise position of generation or loss of $k f-1$, respectively.
Circles or crosses represent species in which the presence or absence of $k f-1$ has been confirmed in the Gen Bank database on January 29, 2009. In the case of sea squirt (Ciona intestinalis), the presence of $k f-1$ is represented by a triangle as only fragmented amino acid sequences have been found similar to those of KF-1. This is probably due to an incomplete determination of genomic sequences. Detailed data on which this illustration is essentially based are given in (A), (B), and (C) 


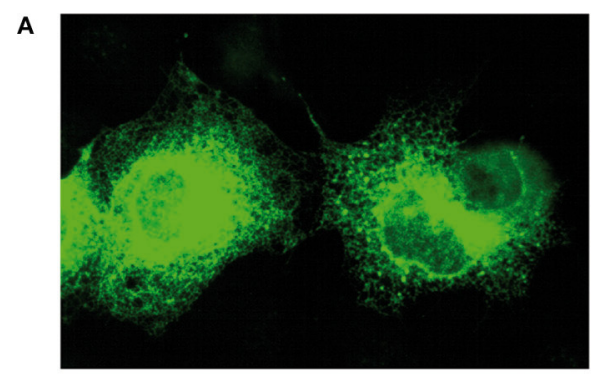

anti PS $\alpha$

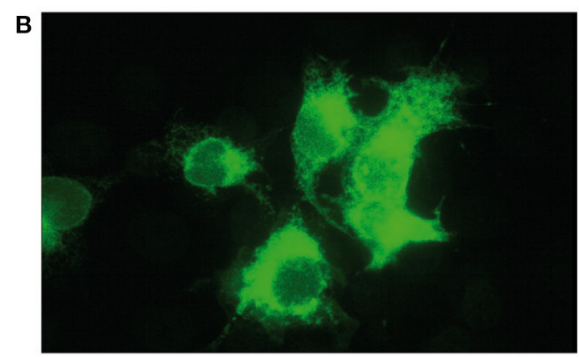

anti PS $\beta$

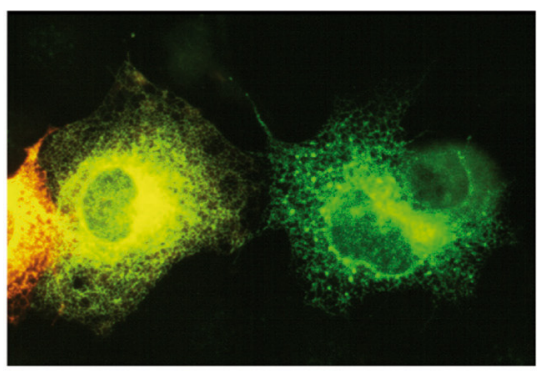

merge

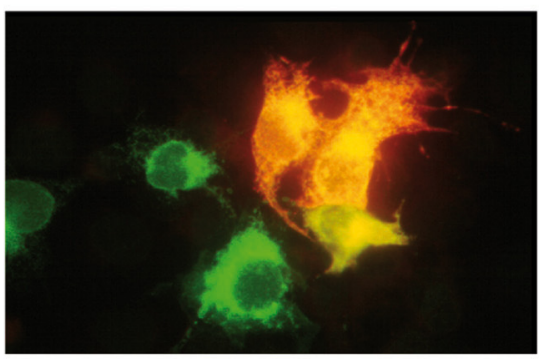

merge

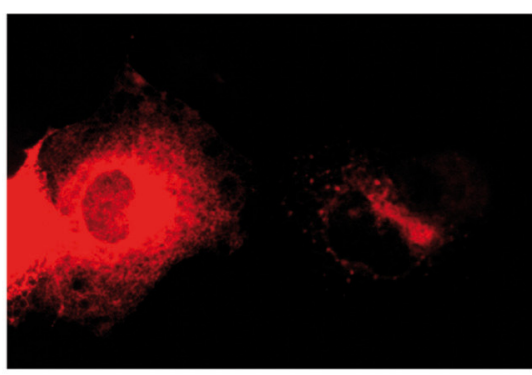

anti Myc (KF-1)

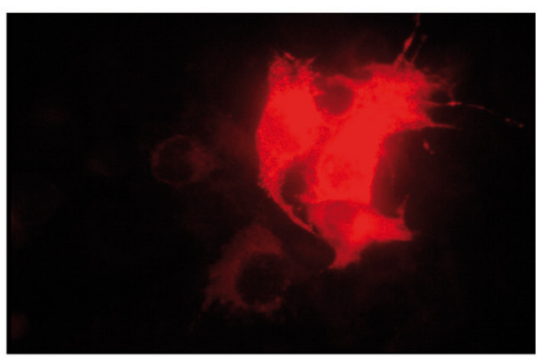

anti Myc (KF-1)
Figure 2 | Immunostaining of Xenopus KF-1 tagged with the Myc epitope and PS $\alpha$ or PS $\boldsymbol{\beta}$ co-expressed in COS-1 cells. (A) Proteins were stained with anti-Myc antibody probed with rhodamin conjugated anti-mouse lgG for KF-1 (red) and anti-PS $\alpha$ (Xenopus PS1 homologue) probed with fluorescein isothiocyanate (FITC) conjugated to anti-rabbit IgG for PS $\alpha$ (green). Images of 'anti Myc (KF-1)' and 'anti PS $\alpha$ ' are merged ('merge'). (B) The same as (A) except PS $\beta$ (Xenopus PS2 homologue) was used instead of PS $\alpha$. KF-1 is co-localized with either PS $\alpha$ or PS $\beta$ as indicated in yellow or orange ('merge').

Table 1 | Behavioral phenotypes of $k f-\mathbf{1}^{-/-}$mice compared to the behavioral phenotypes of $k f-\mathbf{1}^{+/+}$littermates.

\begin{tabular}{|c|c|c|}
\hline Tests & Measurements & Phenotypes $^{a}$ \\
\hline General health examination & Whisker, coat, reflexes & $=$ \\
\hline \multirow[t]{5}{*}{ Physical test } & Body temperature & $=$ \\
\hline & Body weight & $=$ \\
\hline & Wire hanging time & $\uparrow$ \\
\hline & Grip strength & $=$ \\
\hline & Auditory capacity & $=$ \\
\hline Light/dark transition test & Anxiety & $\uparrow$ \\
\hline Open field test & Exploratory locomotion & $=$ \\
\hline Elevated plus maze test & Anxiety & $\uparrow$ \\
\hline Hot plate test & Pain sensitivity (latency time) & $=$ \\
\hline \multirow[t]{5}{*}{ Social interaction test } & Total duration of contacts & $=$ \\
\hline & Number of contacts & $=$ \\
\hline & Total duration of active contacts & $=$ \\
\hline & Mean duration/contact & $=$ \\
\hline & Distance traveled & $=$ \\
\hline Rotarod test & Motor coordination & $=$ \\
\hline Prepulse inhibition (PPI) test & Sensorimotor gating & $\uparrow$ \\
\hline Porsol forced swimming test & Immobility time (behavioral despair) & $=$ \\
\hline T-maze test & Spatial working memory & $=$ \\
\hline \multirow[t]{3}{*}{ Cued and contextual fear conditioning test } & Immediate freezing during conditioning phase & $\uparrow$ \\
\hline & Contextual testing conducted after conditioning & $=$ \\
\hline & Cued test with altered context & $=$ \\
\hline Tail suspension test & Immobility time (behavioral despair) & $=$ \\
\hline
\end{tabular}

The testing order is from the top to the bottom of this table. Further details are presented in Tsujimura et al. (2008). ${ }^{a}=$, no significant difference; $\uparrow$, increased in

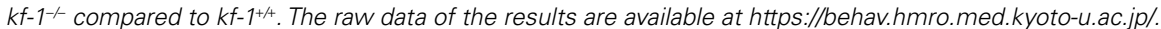


SNP

DNA sequence variation, called single nucleotide polymorphism, occurring on a single nucleotide in the genome among individual members of a species or between paired chromosomes within an individual. 'SNP (pronounced snip)' was defined initially as that with a minor allele frequency of $\geq 1 \%$, but this definition is rather artificial and not meaningful.

Ubiquitination

Ubiquitination (or ubiquitylation) is the post-translational tagging reaction mediated by E3 ubiquitin ligase to a protein with one or more highly conserved peptide molecules called 'ubiquitin' consisting of 76 amino acids. Ubiquitination targets the substrate protein for proteasomal degradation. transitions: $p=0.0392$ ) (Tsujimura et al., 2008). Consistently, the mice also show 'timidity-like' responses under stressful situations, such as prolonged wire-hanging time, enhanced immediate freezing with an aversive foot shock, and decreased locomotor activity at heights (Table 1 and Tsujimura et al., 2008). As significant differences are not observed in body weight and grip strength, and in general exploratory locomotion, the 'timidity-like' responses are likely to be related to psychological but not physical alterations in $k f-1^{-1-}$ mice. This implies that KF-1 plays a role in emotional control by suppressing anxiety at least in mice. In this context, it is of particular interest to note that a number of SNPs are reported in the coding and non-coding exonic regions of human $k f-1$ according to the NCBI's SNP database, and some are supposed to substantially modulate KF-1 activity in homozygous or dual heterozygous carriers; for example, rs35921467 resulting in a frame shift at amino acid position 180 , rs 17857046 and rs 17853383 in critical amino acid substitutions ( $\mathrm{S}$ to $\mathrm{P}$ and $\mathrm{P}$ to $\mathrm{H}$ ) at 251 and 502 , respectively, and rs 11695337 in a termination codon at 626 .

As KF-1 is an E3 ubiquitin ligase located on ER, KF-1 may be responsible for conducting the ERAD pathway, in which some factors promoting anxiety may be targeted. Therefore, the absence or reduction of KF-1 activity may result in 'enhanced anxiety' by increasing putative anxiety promoters (Figure 3A). Regarding serotonergic metabolisms, it is not clear at the moment whether or how the ERAD pathway directed by KF-1 is associated with the serotonergic pathway, and it has to be elucidated in future. However, KF-1's targets for proteasomal degradation should be neither the serotonin receptor $\left(5-\mathrm{HT}_{1 \mathrm{~N}}\right)$ nor the transporter (5-HTT), because a lack of these proteins increases anxiety-like behaviors (Heisler et al., 1998; Holmes et al., 2003).

\section{KF-1 AND PARKIN AS ER-BASED E3 UBIQUITIN LIGASES}

Ubiquitination plays an essential regulatory role in all critical eukaryotic cellular processes. Proteasomal degradation through the ERAD pathway is not an exception. It has been well established that these processes play an important role in a variety of human somatic diseases, ranging from cancer, viral infection, diabetes, and inflammation to muscle wastage and neurodegenerative disorders (see Kostova et al., 2007; Petroski, 2008). However, there are no reports on the animal specific ubiquitin ligase, which is responsible for emotional control or mental disorders.

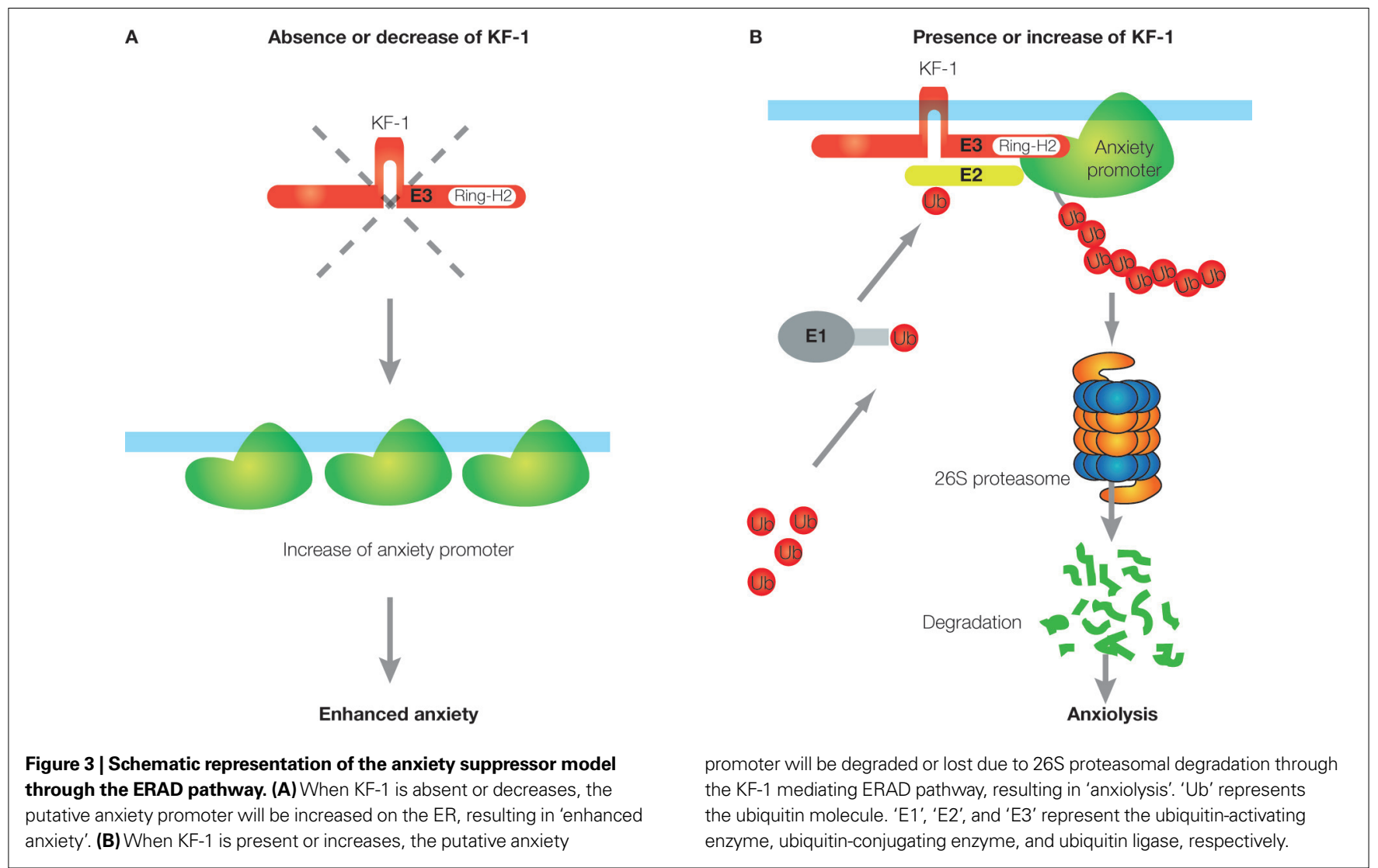


PPI

Prepulse inhibition (PPI) is a neurological phenomenon where a weaker pre-stimulus inhibits the reaction of animals to a subsequent strong startling stimulus.

Sensorimotor gating The brain's ability to filter out the unnecessary information.
Concerning neurodegenerative disorders, Parkin, another ER-ubiquitin ligase, plays a key role in preventing the degeneration of dopaminergic neurons in Parkinson's disease (PD). A recessive mutation in parkin is responsible for the neurodegenerative disorder known as the autosomal recessive juvenile form of Parkinsonism, the most common form of familial PD (Kitada et al., 1998). Human parkin with 12 exons ranging over approximately $1.5 \mathrm{Mb}$ is located on chromosome 6q25.2.27, and encodes an E3 ubiquitin ligase, consisting of 465 amino acids, with two RING finger motifs. Parkin substrates have been identified being degraded through the ERAD pathway, such as Pael-R, CDCrel-1, $\alpha$-Syn, and synphilin-1 (Yang et al., 2003). The accumulation of these proteins in dopaminergic neurons leads to ER stress-induced apoptosis, resulting in PD (see von Coelln et al., 2004). Promoting their degradation would aid PD patients by preventing neurodegeneration. In fact, the neuronal synthesis of the Parkin substrate Pael-R has been shown to cause a loss of dopaminergic cells in transgenic Drosophila models. The co-expression of parkin results in the degradation of Pael- $\mathrm{R}$ and nearly completely blocks neurodegeneration, whereas interfering with the function of endogenous Drosophila Parkin promotes Pael-R accumulation and augments its toxicity (Yang et al., 2003). Hence, the over-expression of parkin has emerged as a powerful approach to PD with complementary effects to approaches described for the use of neurotrophic factors against PD (Ulusoy and Kirik, 2008). An analogy could be made by having such Drosophila models to study the role of KF-1 in anxiety/depression. However, the analogy may not be feasible as no evidence is available for the involvement of neuronal cell death in anxiety/depression, and $k f-1$ is absent in Drosophila (Figure 1D). It should be noted that $k f-1^{-1-}$ mice have increased PPI values (Table 1), which implies that at least one of the KF-1 target proteins is involved in regulation of sensorimotor gating. In such cases, over-expression of $k f-1$ might cause serious side effects as the PPI values are usually reduced in schizophrenic patients. Despite this, one cannot rule out the possibility of $k f-1$ up-regulation as an anxiolytic/antidepressant treatment.

Instead, $k f-1^{-/-}$mice provide a powerful tool for some pharmacological approaches to anxiety/ depression. For example, by using the mice, one can identify the putative anxiety promoters that are degraded through the ERAD pathway mediated by KF-1 and are responsible for the sensitivity to potential signs of danger or to stressful situations (Figures 3A,B). KF-1 substrates acting as anxiety promoter may be found by the computed differential screening in 2-dimensional gel electrophoresis (see Marengo et al., 2008) of cell homogenates derived from the frontal cortex or hippocampus of $k f-1^{-l-}$ and $k f-1^{+/+}$mice. As the

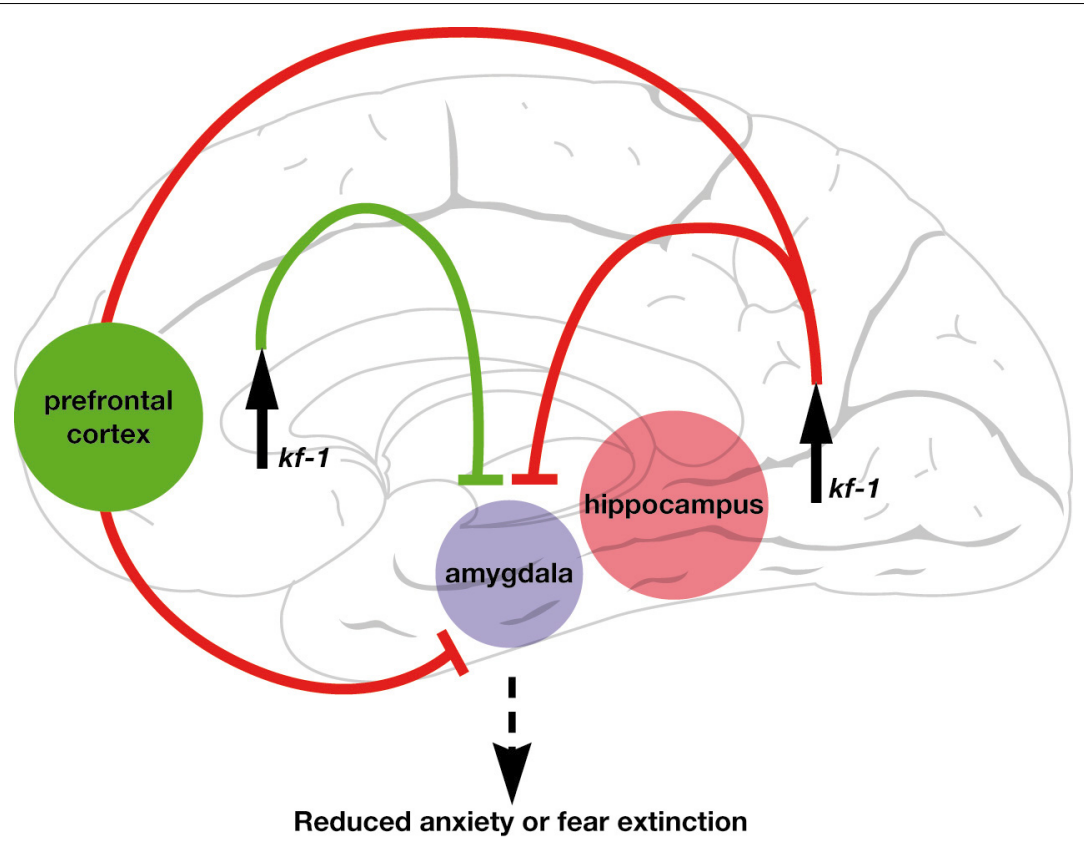

Figure 4 | A circuitry presentation of the anxiety suppressor model by the up-regulation of $k f-1$ expression. The circuitry model was constructed by considering the fear extinction neural model (Sotres-Bayon et al., 2006). The anxiolytic pathway after $k f-1$ up-regulation is incorporated into the model. 
expression of $k f-1$ is up-regulated in the frontal cortex and hippocampus after antidepressant treatments, it is likely that the anxiolytic/antidepressive effect of KF-1 functions primarily in these tissues and that their inhibitory signals are transmitted to the amygdala to prevent the manifestation of anxiety or fear (Figure 4). This proposal may be highly hypothetical and hence has to be elucidated in future studies. To conclude, examining $k f-1^{-1-}$ mice in a simple light/dark transition test is an effective method of screening novel anxiolytic/antidepressant drugs that inhibit the putative anxiety promoters.

\section{ACKNOWLEDGEMENTS}

WearegratefultoDrs.M.Matsuki, and K. Yamanishi for their collaborations during this work, and Messrs. N. Matsumoto and T. Aramaki, and Drs. H. Yamagishi, S. Clapcote, and M. Nakagawa for their support and helpful advices to our work. THG thanks Drs. T. Mizuno, K. Yasojima, Y. Ariga, Y. Fukumaki, C. Mitchell and M. Miyata for valuable discussions and comments. NI is a recipient of Grant-in-Aid for Scientific Research on Priority Area "Comparative Genomics" from the Ministry of Education, Culture, Sports, Science and Technology of Japan.

\section{REFERENCES}

Bishop, S. J. (2007). Neurocognitive mechanisms of anxiety: an integrative account. Trends Cogn. Sci. 11, 307-316.

Carvalho,P., Goder, V., and Rapoport, T. A. (2006). Distinct ubiquitin-ligase complexes define convergent pathways for the degradation of ER proteins. Cell $126,361-373$.

Chen, C., Rainnie, D. G., Greene, R. W., and Tonegawa, S. (1994). Abnormal fear response and aggressive behavior in mutant mice deficient for $\alpha$-calcium-calmodulin kinase II. Science 266, 291-294.

Darwin, C. (1872). The Expression of the Emotions in Man and Animals. Chicago, University of Chicago Press, reprinted in 1965.

Gogos, J. A., Morgan, M., Luine, V., Santha, M., Ogawa, S., Pfaff, D., and Karayiorgou, M. (1998). CatecholO-methyltransferase-deficient mice exhibit sexually dimorphic changes in catecholamine levels and behavior. Proc. Natl. Acad. Sci. U.S.A. 95, 9991-9996.

Hashimoto-Gotoh, T., Tsujimura, A., and Watanabe, Y. (2006). Presenilins: clarification of contradictory observations using molecular and developmental animal models. J. Kyoto Prefect. Univ. Med. 115, 809-825. Available at: www.eonet. ne.jp/ kpum/Presenilin_files/ Hashimoto_GotohModel.pdf.

Hashimoto-Gotoh, T., Tsujimura, A., Watanabe, Y., Iwabe, N., Miyata, T., and Tabira, T. (2003). A unifying model for functional difference and redundancy of presenilin- 1 and -2 in cell apoptosis and differentiation. Gene 323, 115-123.

Heisler, L. K., Chu, H.-M., Brennan, T. J., Danao, J. A., Bajwa, P., Parsons, L. H., and Tecott, L. H. (1998). Elevated anxiety and antidepressant-like responses in serotonin $5-\mathrm{HT}_{1 \mathrm{~A}}$ receptor mutant mice. Proc. Natl. Acad. Sci. U.S.A. 95, 15049-15054.
Holmes, A., Yang, R. J., Lesch, K.-P., Crawley,J.N., and Murphy,D.L. (2003). Mice lacking the serotonin transporter exhibit 5- $\mathrm{HT}_{1 \mathrm{~A}}$ receptor-mediated abnormalities in tests for anxiety-like behavior. Neuropsychopharmacology 28, 2077-2088.

Katoh, K., Kuma, K., and Miyata, T. (2001). Genetic algorithm-based maximum-likelihood analysis for molecular phylogeny. J. Mol. Evol. 53, 477-484.

King, N., Westbrook, M. J., Young, S. L., Kuo, A., Abedin, M., Chapman, J., Fairclough, S., Hellsten, U., Isogai, Y., Letunic, I., Marr, M., Pincus, D., Putnam, N., Rokas, A., Wright, K. J., Zuzow, R., Dirks, W., Good, M., Goodstein, D., Lemons, D., Li, W. Lyons, J. B., Morris, A., Nichols, S., Richter, D. J., Salamov, A., Sequencing, J. G., Bork, P., Lim, W. A., Manning, G., Miller, W. T., McGinnis, W., Shapiro, H., Tjian, R., Grigoriev, I.V., and Rokhsar, D. (2008). The genome of the choanoflagellate Monosiga brevicollis and the origin of metazoans. Nature 451, 783-788.

Kitada, T., Asakawa, S., Hattori, N., Matsumine, H., Yamamura, Y., Minoshima, S., Yokochi, M., Mizuno, Y., and Shimizu, N. (1998). Mutations in the parkin gene cause autosomal recessive juvenile parkinsonism. Nature 392, 605-608.

Kortschak, R. D., Samuel, G., Saint, R., and Miller,D. J. (2003). EST analysis of the cnidarian Acropora millepora reveals extensive gene loss and rapid sequence divergence in the model invertebrates. Curr. Biol. 13, 2190-2195.

Kostova,Z., Tsai,Y.C., and Weissman, A. M. (2007). Ubiquitin ligases, critical mediators of endoplasmic reticulumassociated degradation. Semin. Cell Dev. Biol. 18, 770-779.

Kovacs, D. M., Fausett, H. J., Page, K. J., Kim, T.W., Moir, R.D., Merriam, D. E., Hollister, R. D., Hallmark, O. G., Mancini, R., Felsenstein, K. M., Hyman, B. T., Tanzi, R. E., and
Wasco, W. (1996). Alzheimerassociated presenilins 1 and 2: neuronal expression in brain and localization to intracellular membranes in mammalian cells. Nat. Med. 2, 224-229.

Kudo, K., Yamada, M., Takahashi, K., Nishioka, G., Tanaka,S., Hashiguchi, T., Fukuzako, H., Takigawa, M., Higuchi, T.,Momose, K., Kamijima, K., and Yamada, M. (2005). Repetitive transcranial magnetic stimulation induces $k f-1$ expression in the rat brain. Life Sci. 76, 2421-2429.

Levinson, D. F. (2006). The genetics of depression. Biol. Psychiatry 60 84-92.

Lorick, K. L., Jensen, J. P., Fang, S., Ong, A. M., Hatakeyama, S., and Weissman, A. M. (1999). RING fingers mediate ubiquitin-conjugating enzyme (E2)-dependent ubiquitination. Proc. Natl. Acad. Sci. U.S.A. 96 11364-11369.

Lorick, K. L., Yang, Y., Jensen, J. P., Iwai, K., and Weissman, A. M. (2006). Studies of the ubiquitin proteasome system. Curr. Protoc. Cell Biol. Chapter 15, Unit 15.9.

Lundkvist, J., and Näslund, J. (2007). $\gamma$-Secretase: a complex target for Alzheimer's disease. Curr. Opin. Pharmacol. 7, 112-118.

Marengo, E., Robotti, E., and Bobba, M. (2008). 2D-PAGE maps analysis. Methods Mol. Biol. 428, 291-325.

Maruyama, Y., Yamada, M., Takahashi, K., and Yamada, M. (2008). Ubiquitin ligase KF-1 is involved in the endoplasmic reticulum-associated degradation pathway. Biochem. Biophys. Res. Commun. 374, 737-741.

Miller, D. J., and Ball, E. E. (2008). Animal evolution: Trichoplax, trees, and taxonomic turmoil. Curr. Biol. 18 R1003-R1005.

Miyakawa, T., Leiter, L. M., Gerber, D. J., Gainetdinov, R. R., Sotnikova, T. D., Zeng, H., Caron, M. G., and Tonegawa, S. (2003). Conditional calcineurin knockout mice exhibit multiple abnormal behaviors related to schizophrenia. Proc. Natl. Acad. Sci. U.S.A. 100, 8987-8992.

Miyakawa, T., Yagi, T., Watanabe, S., and Niki, H. (1994). Increased fearfulness of Fyn tyrosine kinase deficient mice. Brain Res. Mol. Brain Res. 27, 179-182.

Nakajima, R., Takao, K., Huang, S. M., Takano, J., Iwata, N., Miyakawa, T., and Saido, T. C. (2008). Comprehensive behavioral phenotyping of calpastatin-knockout mice. Mol. Brain 1, 7 .

Nishioka, G., Yamada, M., Kudo, K., Takahashi, K., Kiuchi, Y., Higuchi, T. Momose, K., Kamijima, K., and Yamada, M. (2003). Induction of $k f-1$ after repeated electroconvulsive treatment and chronic antidepressant treatment in rat frontal cortex and hippocampus. J. Neural. Transm. 110, 277-285.

Petroski, M.D. (2008). The ubiquitin system, disease, and drug discovery. $B M C$ Biochem. 9, S7. doi: 10.1186/14712091-9-S1-S7. Available at: http:// www.pubmedcentral.nih.gov/ picrender.fcgi?artid $=2582801 \&$ blob type $=$ pdf

Porsolt, R. D., Anton, G., Blavet, N., and Jalfre, M. (1978). Behavioural despair in rats: A new model sensitive to antidepressant treatments. Eur. J. Pharmacol. 47, 379-391.

Ringman, J. M., Diaz-Olavarrieta, C. Rodriguez, Y., Chavez, M., Paz, F., Murrell, J., Macias, M. A., Hill, M., and Kawas, C. (2004). Female preclinical presenilin-1 mutation carriers unaware of their genetic status have higher levels of depression than their non-mutation carrying kin. J. Neurol. Neurosurg. Psychiatr. 75, 500-502.

Schubert, P. (1993). Trichoplax adhaerens (Phylum Placozoa) has cells that react with antibodies against the neuropeptide RFAmide. Acta Zoologica 74, 115.

Sotres-Bayon, F., Cain, C. K., and LeDoux, J. E.(2006).Brainmechanisms of fear extinction: historical perspectives on the contribution of prefrontal cortex. Biol. Psychiatry 60, 329-336. 
Srivastava, M., Begovic, E., Chapman, J., Putnam, N. H., Hellsten, U., Kawashima, T., Kuo, A., Mitros, T., Salamov, A., Carpenter, M. L., Signorovitch, A. Y., Moreno, M. A., Kamm, K., Grimwood, J., Schmutz, J., Shapiro, H., Grigoriev, I.V., Buss, L.W., Schierwater, B., Dellaporta, S. L., and Rokhsar, D. S. (2008). The Trichoplax genome and the nature of placozoans. Nature 454, 955-960.

Steru, L., Chermat, R., Thierry, B., and Simon, P. (1985). The tail suspension test: a new method for screening antidepressants in mice. Psychopharmacology (Berl). 85, 367-370.

Tsujimura, A., Matsuki, M., Takao, K., Yamanishi, K., Miyakawa, T., and Hashimoto-Gotoh, T. (2008). Mice lacking the $k f-1$ gene exhibit increased anxiety - but not despair-like behavior. Front. Behav. Neurosci. 2, 4. doi: 10.3389/neuro.08.004.2008. Available at: http://www.frontiersin.org/ behavioralneuroscience/paper/10.3389/ neuro.08/004.2008/pdf/.
Uher, R., and McGuffin, P. (2008). The moderation by the serotonin transporter gene of environmental adversity in the aetiology of mental illness: review and methodological analysis. Mol. Psychiatry 13, 131-146.

Ulusoy, A., and Kirik, D. (2008). Can overexpression of parkin provide a novel strategy for neuroprotection in Parkinson's disease? Exp. Neurol. 212, 258-260.

von Coelln, R., Dawson, V. L., and Dawson, T. M. (2004). Parkinassociated Parkinson's disease. Cell Tissue Res. 318, 175-184.

Yamada, M., Yamada, M., Yamazaki, S., Takahashi, K., Nishioka, G., Kudo, K., Ozawa, H., Yamada, S., Kiuchi, Y., Kamijima, K., Higuchi, T., and Momose, K. (2000). Identification of a novel gene with RING-H2 finger motif induced after chronic antidepressant treatment in rat brain. Biochem. Biophys. Res. Commun. 278, 150-157. Yamasaki, N., Maekawa,M., Kobayashi, K., Kajii,Y., Maeda, J., Soma, M., Takao, K.,
Tanda, K., Ohira, K., Toyama, K., Kanzaki, K., Fukunaga, K., Sudo, Y., Ichinose, H., Ikeda, M., Iwata, N. Ozaki, N., Suzuki, H., Higuchi, M. Suhara, T., Yuasa, S., and Miyakawa, T. (2008). $\alpha$-CaMKII deficiency causes immature dentate gyrus, a novel candidate endophenotype of psychiatric disorders. Mol. Brain 1, 6.

Yang, Y., Nishimura, I., Imai, Y., Takahashi, R., and Lu, B. (2003). Parkin suppresses dopaminergic neuron-selective neurotoxicity induced by Pael-R in Drosophila. Neuron 37, 911-924.

Yang, Z. (1994). Maximum likelihood phylogenetic estimation from DNA sequences with variable rates over sites: approximate methods. J. Mol. Evol. 39, 306-314.

Yasojima, K., Tsujimura, A., Mizuno, T., Shigeyoshi, Y., Inazawa, J., Kikuno, R. Kuma, K., Ohkubo, K., Hosokawa, Y. Ibata, Y., Abe, T., Miyata, T. Matsubara, K., Nakajima, K., and Hashimoto-Gotoh, T. (1997). Cloning of human and mouse cDNAs encoding novel zinc finger proteins expressed in cerebellumandhippocampus. Biochem. Biophys. Res. Commun. 231, 481-487.

Conflict of Interest Statement: The authors declare that the research was conducted in the absence of any commercial or financial relationships that could be construed as a potential conflict of interest.

Received: 29 January 2009; paper pending published: 17 February 2009; accepted: 27 February 2009; published: 01 May 2009. Citation: Front. Neurosci. (2009) 3,1: 15-24. doi: 10.3389/neuro.01.004.2009

Copyright (c) 2009 Hashimoto-Gotoh, Iwabe, Tsujimura, Takao and Miyakawa. This is an open-access article subject to an exclusive license agreement between the authors and the Frontiers Research Foundation, which permits unrestricted use, distribution, and reproduction in any medium, provided the original authors and source are credited. 